\title{
SPLINT THERAPY FOR TREATMENT OF ANTERIOR DISC DISPLACEMENT WITH REDUCTION
}

\author{
Nadia Galal Mohamed* and Omniya Mohamed Abd El Azizi**
}

\begin{abstract}
The aim of the study is to assess the efficacy of the Lingual Ring Splint (LS), anterior repositioning splint (ARS) and stabilizing splint (SS) in management of anterior disc displacement with reduction (DDWR) for the relief of pain and improving mandibular movements. Thirty patients diagnosed with DDWR were included in this study. The participants were randomly assigned into one of three equal groups using a computer-generated randomization schedule receiving the assigned splint for each group, with specific instructions regarding the time of using it and exercises. Follow up was made after 1 and 6 months to test pain score and mandibular range of motion. Pain score improved in all 3 groups with statistical significance with better results is SS group than other two splints. Also, there was an increase in maximum mouth opening (MMO) with the highest measurements in SS group with statistical significance difference. There was no statistical difference regarding lateral excursion between all groups.
\end{abstract}

KEYWORDS: anterior disc displacement, stabilizing splint, anterior repositioning splint, lingual ring splint

\section{INTRODUCTION}

Psychological agitation, functional disability and limitations of the orofacial system have a huge impact on normal life of patients with temporomandibular disorders (TMDs) ${ }^{1}$. Anterior Disc Displacement with reduction (DDWR) either unilateral or bilateral is the main finding in the majority of patients with TMDs². Epidemiologicaly, about $10 \%$ to $15 \%$ of the population has TMDs; $5 \%$ of which require treatment. The prevalence of
TMDs is highest between 18 and 45 years of age and of highest occurrence in women ${ }^{3}$.

Treatment modalities for DDWR range from educating the patient to surgical intervention. Reassurance, medication, Physical therapy, hot fomentations, splint therapy. ultrasound and massage.

The most recommended treatment for TMD is occlusal splints, especially stabilisation splints $^{1,2.3}$ as they provide ideal centric relation, reducing

\footnotetext{
* Associate Professor, Oral and Maxillofacial Department. Faculty of Dentistry, Cairo University

** Lecturer, Oral and Maxillofacial Department, Faculty of Dentistry, Cairo University.
} 
abnormal muscle activity leading to the so-called 'neuromuscular balance' in the masticatory system

Anterior repositioning splint (ARS) allows the mandible to assume an anterior position to centric occlusion, providing a more favorable condyle-disc relationship in the fossa so that normal function can be established. The goal is to eliminate the signs and symptoms associated with disc-interference disorders. Maintaining the mandible in temporary therapeutic position in which click is eliminated and thereby allowing the disc to reposition ${ }^{5}$

The lingual ring fig (1) is an innovative universal device, as of the research by Dr. Alessandro Rampello ${ }^{6}$. It's not only a cushion between teeth, but also a rehabilitator positional device of the craniomandibular components, combining more synergistic action such as, raising the tongue and hyoid bone, repositioning the mandible and the condyle and disconnecting the dental contacts.

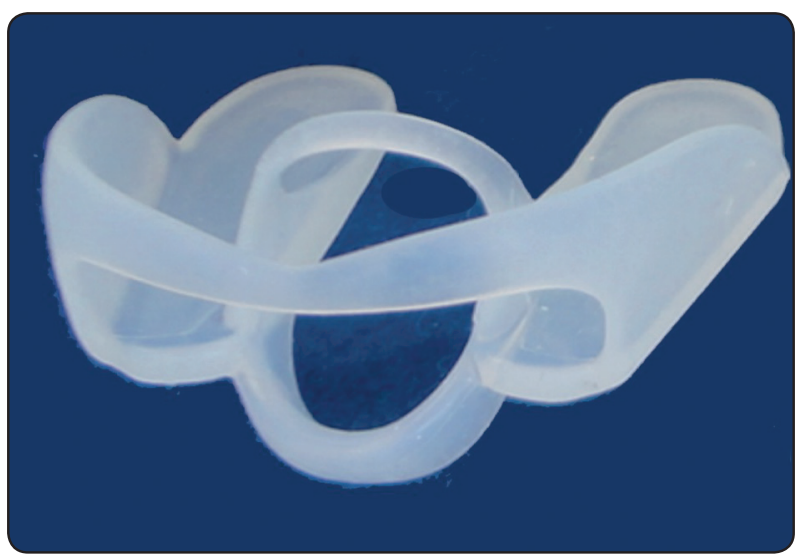

Fig. (1): Lingual Ring splint.

\section{PATIENTS AND METHODS}

This is a randomized control trial which consisted of 30 patients of both genders with signs of disc displacement with reduction and TMJ pain. Patients were recruited from the outpatient clinic of the Department of Oral and Maxillofacial Surgery, Faculty of Dentistry, Cairo University.
Inclusion criteria: adult patients over age of 18 , reporting of pain in pre-auricular area that is worsened by functional activity such as chewing.

Patients suffering from any systemic conditions that may affect the TMJ, and patients who have done previous surgical treatment were excluded from the study.

Clinical assessment of temporomandibular joints and masticatory muscles was done according to DC/ TMD recommendations.

The patients were randomly assigned to ARS, SS, or LS groups. Pain was measured using Visual analog scale (VAS), where 0 indicated "no pain" and 10 indicated "the worst possible pain" with palpation. Maximum mouth opening (MMO), right and left lateral excursions were measured using the digital calliper. These evaluations were done at the following time points: pre-treatment, 1 month and 6 months post treatment.

\section{Therapeutic protocol}

Regarding the lingual ring, patients were advised to wear the splint during sleep at least 8 hours. The device was placed three times morning and evening and instructed to exercise by opening and closing in the centric occlusion with the tongue in the ring in spotting point 30 times for half an hour each time. Another exercise is to swallow the saliva 30 times.

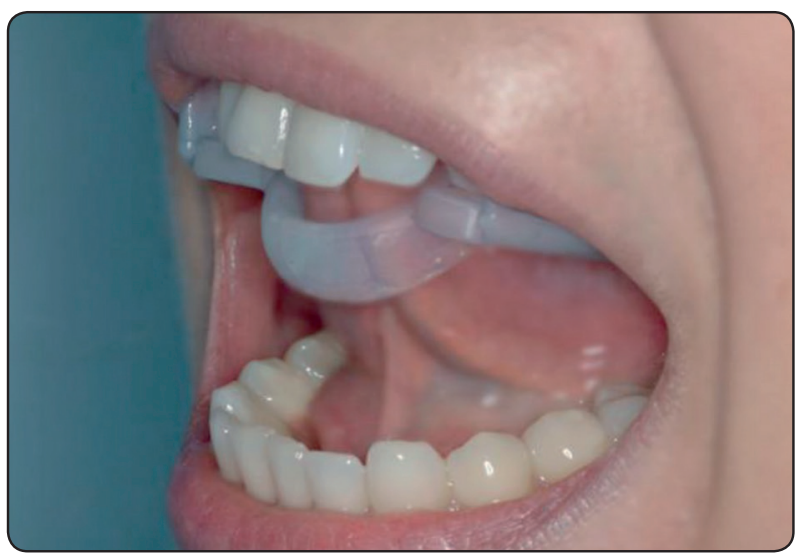

Fig. (2) Photograph showing the position of the tongue in the ring during opening. 
As for Anterior repositioning splint and stabilization splint, patients were instructed to wear the device 2 to 6 hours per day according to the severity of the case.

\section{Statistical analysis}

Statistical analysis was performed using SPSS (Statistical package for the social sciences- IBM $^{\circledR}$ SPSS $^{\circledast}$ Statistics Version 20 for Windows, IBM Corp., Armonk, NY, USA). Quantitative data was represented as mean \pm standard deviation. One way AN§OVA test was used to compare variables between the three groups, and Bonferroni correction was used for multiple comparisons. The results were considered statistically significant if the $\mathrm{p}$ value was less than 0.05 .

\section{RESULTS}

Assessing pain; the preoperative pain was comparable in the three groups, $7.4 \pm 1.5$ for SS group, $7.2 \pm 1.03$ for LS group, and $7.1 \pm 1.19$ for ARS group. There was no statistically significant difference between all groups ( $\mathrm{P}$ value 0.864 ). After 1 months the lowest pain was recorded for ARS group $(5.1 \pm 1.45)$, followed by the LS group $(6.2 \pm 0.63)$, and finally the SS group $(7.2 \pm 1.39)$. There was a statistically significant difference between ARS and SS groups (P value 0.002). After 6 months the lowest pain was recorded for the SS group (2.7 \pm 1.25$)$, followed by the ARS group (3 $\pm 0.67)$, and finally the LS group $(4.7 \pm 0.67)$. There was a statistically significant difference between LS group and both SS and ARS groups (P value 0, 0.001 respectively).

Regarding maximum mouth opening, the preoperative MMO was comparable in the three groups, $36.9 \pm 3.44 \mathrm{~mm}$ for the SS group, $37.5 \pm$ $3.69 \mathrm{~mm}$ for the ARS group, and $36.4 \pm 3.62 \mathrm{~mm}$ for the LS group. There was no statistically significant difference between all groups ( $P$ value 0.792 ). After 1 months, the ARS group showed the highest increase in MMO $(1.2 \pm 1.14 \mathrm{~mm})$, followed by the LS group $(1.1 \pm 0.99 \mathrm{~mm})$, finally the SS group $(0.3$ $\pm 0.483 \mathrm{~mm})$. There was no statistically significant difference between all groups ( $\mathrm{P}$ value 0.072). After 6 months, the SS group showed the highest increase in MMO $(5.5 \pm 2.59 \mathrm{~mm})$, followed by the ARS group $(3.3 \pm 1.2)$, finally the LS group $(0.60 \pm 0.96$ $\mathrm{mm})$. There was statistically significant difference between all groups ( $\mathrm{P}$ value $0.028 \mathrm{SS}$ and ARS, 0.006 ARS and LS, 0 SS and LS).

For the right lateral excursion, the preoperative RT excursion in the SS group was $6.30 \pm 1.34 \mathrm{~mm}$ while the ARS group $4.40 \pm 1.17 \mathrm{~mm}$ and the LS group $4.40 \pm 1.17 \mathrm{~mm}$. There was a statistically significant difference between SS group and both LS and ARS groups (P value 0.006, 0.006 respectively). After 1 month, the increase in RT excursion was comparable in the 3 groups (SS group $0.30 \pm 0.48 \mathrm{~mm}$, ARS $0.30 \pm 0.48 \mathrm{~mm}$, LS group $0.30 \pm 0.48 \mathrm{~mm}$ ). There was no statistically significant difference between all groups ( $\mathrm{P}$ value 1). After 6 months, the increase in RT excursion was comparable in the 3 groups (SS group $0.80 \pm 0.92$ $\mathrm{mm}$, ARS $1.0 \pm 1.25 \mathrm{~mm}$, LS group $1.0 \pm 1.25 \mathrm{~mm}$ ). There was no statistically significant difference between all groups (P value 0.904).

About the left lateral excursion; the preoperative LT excursion in the SS group was $5.80 \pm 1.55 \mathrm{~mm}$ while the ARS group $4.7 \pm 1.16 \mathrm{~mm}$ and the LS group $0.7 \pm 0.82 \mathrm{~mm}$. There was a no statistically significant difference between SS group and both LS and ARS groups (P value 0.083 respectively). After 1 month, the increase in LT excursion was comparable in the 3 groups (SS group $0.70 \pm 0.82$ $\mathrm{mm}$, ARS $0.40 \pm 0.69 \mathrm{~mm}$, LS group $0.50 \pm 0.71$ $\mathrm{mm}$ ). There was no statistically significant difference between all groups (P value 0.661). After 6 months, the increase in LT excursion was comparable in the 3 groups (SS group $0.80 \pm 1.03 \mathrm{~mm}$, ARS $0.70 \pm$ $0.82 \mathrm{~mm}$, LS group $0.70 \pm 0.82 \mathrm{~mm}$ ). There was no statistically significant difference between all groups (P value 0.96). 


\section{DISCUSSION}

The Guidelines of the Royal College of Dental Surgeons of Ontario, $2006{ }^{7}$ clearly specified that conservative methods should always be firstly implied in management of TMDs. Failure to manage the symptoms with conservative treatment does not implicate the success of more invasive technique.

Numerous studies have been conducted to study the effectiveness of different non-invasive techniques. Most of which, the ones managing cases of internal derangement focused on relieving pain and functional limitation. Guided by the preliminary results of $\mathrm{T}$. Badelet $\mathrm{al}^{8}$, the present study was designed to assess the efficacy of anterior repositioning splint compared with stabilizing and Lingual splint in patients with anterior disc displacement with reduction.

The most common derangements of the condyledisc complex is disc displacement with reduction ${ }^{9}$. The use of ARS unloads the TMJ tissue including retrodiscal tissues and insertions of selected masticatory muscles to articular discs and that's why it is considered to play an important role in the treatment of disc displacement. In the current study, ARS showed a significant reduction of pain and increase in maximum mouth opening after 1 month followed by the lingual splint and lastly stabilizing splint, but on the other hand after 6 month the stabilizing splint showed the most significant reduction of pain, and increase in maximum mouth openning followed by the ARS and lastly the lingual Ring splint. Management of pain related to TMJ disc displacement using ARS has been also positively evaluated by other authors ${ }^{(10,11,12)}$

Nur Hersek et al ${ }^{13}$ found reduction of the pain with the use of anterior repositioning splint (ARS) in $88.2 \%$ and mean vertical opening $42.17 \mathrm{~mm}$ before treatment increased to $45.06 \mathrm{~mm}$. The Lingual splint showed a significant reduction in pain as compared to ARS, mouth opening has significantly improved as well. On the other hand; ARS showed posterior or lateral open bite drawback after few months.
The mechanism of action of the lingual ring is both (Physical treatment part), and (Splint therapy part). Counteracting the load of the vertical muscles (masseters, internal pterygoids, and temporalis); the lower part of the device (Lower Arch), guides the front repositioning of the mandible. This device stimulates the elongation of all muscles, both vertical and horizontal (external Pterygoids and Buccinators), and guiding at the same time the tongue position to remain higher and move forward. The new posture of the mandible and tongue consequently favors an alteration of the position of the hyoid bone. The lingual ring therefore, influences and affects all these components in a more complete manner.

Tsuga et al ${ }^{14}$ studied the stabilization splint and showed that $87 \%$ had relief of pain and $50 \%$ had complete relief after 4 weeks, which complies with the results of the current study. stabilization splint showed better effect in pain reduction, which is in accordance with the results of Fricton et al. ${ }^{15}$

However, stabilization splint showed few drawbacks as time-consumption during fabrication and wearing off resulting in malocclusion during the time of therapy. These drawbacks are absent in lingual splint which is a ready-made device, of highly resilient, nontoxic, hypoallergic, silicone. Its thickness is $3 \mathrm{~mm}$ in the occlusal part subjected to load, and $2 \mathrm{~mm}$ at the remaining part.

In evaluation of lateral excursion, our results demonstrated that there were no significant differences between all groups.

\section{SUMMARY \& CONCLUSION}

ARS showed a significant reduction of pain and increase in maximum mouth opening after 1 month followed by the lingual splint and lastly stabilizing splint, but on the other hand after 6 month the stabilizing splint showed the most significant reduction of pain, and increase in MMO followed by the ARS and lastly the lingual splint. 


\section{REFERENCES}

1. Kuzmanovic Pficer J, Dodic S, Lazic V, Trajkovic G, Milic N, Milicic B. Occlusal stabilization splint for patients with temporomandibular disorders: Meta-analysis of short and long term effects. PLoS One. 2017;12(2):0171296

2. Summer JD, Westesson PL. Mandibular repositioning can be effective in treatment of reducing TMJ disk displacement. A long-term clinical and MR imaging follow-up. Cranio. 1997;15(2):107-120.

3. Roldán-Barraza C, Janko S, Villanueva J, Araya I, Lauer H-C. A systematic review and meta-analysis of usual treatment versus psychosocial interventions in the treatment of myofascial temporomandibular disorder pain. J oral facial pain headache. 2014;28(3):205-222.

4. Okeson JP. Management of Temporomandibular Disorders and Occlusion. Mosby Elsevier; 2008.

5. 5 Ré J-P, Perez C, Darmouni L, Carlier JF, Orthlieb J-D. The occlusal splint therapy. Int J Stomatol Occlusion Med. 2009;2(2):82-86.

6. Rampello A, Papi P, Pompa G, Rampello A, Polimeni A, Paolo CDI. A novel universal device " LINGUAL RING Ri .P.A.Ra " for TMDs and cranio-cervicomandibular pains : preliminary results of a randomized control clinical trial. 2018:1180-1190.

7. R.College,"RCDSO_Guidelines_Diagnosis_and_Management_of_TMD 2009,” no. February 2006, pp. 1-11, 2009.

8. T. Badel, V. Lajnert, and D. Zadravec, "Michigan splint and treatment of temporomandibular joint Michiganska udlaga i liječenje temporomandibularnog zgloba," vol. 49, no. 2, pp. 112-120, 2013.

9. E. L. SchiDman, A. M. Velly, J. O. Look et al., "Effects of four Treatment strategies for temporomandibular joint closed lock,"International Journal of Oral and Maxillofacial Surgery, vol. 43, no. 2, pp. 217-226, 2014.

10. P. C. Conti, C. N. dos Santos, E. M. Kogawa, A. C. de Castro Ferreira Conti, and R. de Araujo Cdos, “,e treatment of painful temporomandibular joint clicking with oral splints: a randomized clinical trial," Journal of American Dental Association, vol. 137, no. 8, pp. 1108-1114, 2006.

11. S. Tecco, S. Caputi, S. Tet'e, G. Orsini, and F. Festa, "Intraarticular and muscle symptoms and subjective relief during TMJ internal derangement treatment with maxillary anterior repositioning splint or SVED and MORA splints: a comparison with untreated control subjects," Journal of Craniomandibular and Sleep Practice, vol. 24, no. 2, pp. 119-129, 2006.

12. P. C. Conti, J. E. Miranda, A. C. Conti, L. F. Pegoraro, and R. Ara'ujo Cdos, "Partial time use of anterior repositioning splints in the management of TMJ pain and dysfunction: a one-year controlled study," Journal of Applied Oral Sciences, vol. 13, no. 4, pp. 345-350, 2005.

13. Hersek N, Uzun G, Cindas A, Canay S, Kutsal YG. Effect of Anterior Repositioning Splints on the Electromyographic Activities of Masseter and Anterior Temporalis Muscles. Cranio®. 1998; 16 (1): 11-16.

14. Tsuga K, Akagawa Y, Sakaguchi R, Tsuru H. A shortterm evaluation of the effectiveness of stabilizationtype occlusal splint therapy for specific symptoms of temporomandibular joint dysfunction syndrome. J Prosthet Dent. 1989; 61 (5): 610-613.

15. T. Haketa, K. Kino, M. Sugisaki, M. Takaoka, and T. Ohta,v "Randomized clinical trial of treatment for TMJ disc displacement," Journal of Dental Research, vol. 89, no. 11, pp. 1259-1263, 2010. 